\title{
ENSINO DE CIÊNCIAS: CONCEITOS DE ECOLOGIA E EVOLUÇÃO MINISTRADOS ATRAVÉS DE OFICINAS
}

\author{
PIRES, Larissa Marques ${ }^{1}$ \\ ALVES, Lucinéia ${ }^{2}$
}

\begin{abstract}
RESUMO
Ensinar ciências é privilegiar situações de aprendizagem que possibilitem ao aluno a formação de sua bagagem cognitiva. As oficinas de Ciências podem ser utilizadas como estratégias didáticas, pois constituem um mecanismo importante na construção de conhecimento. O principal objetivo do presente trabalho foi levar os alunos da Educação Infantil e do Ensino Fundamental, com idade entre 04 e 55 anos, a compreender conceitos de Ecologia e Evolução, através do desenvolvimento de Oficinas, realizadas em 2011 e 2012. Durante as atividades, a maioria dos alunos participou e se interessou. Entretanto, alguns pontos abordados provaram ser desconhecidos, principalmente para alunos do Ensino Fundamental, o que confirma o quanto o ensino da Evolução ainda precisa receber mais atenção nas escolas, assim como a Ecologia deve ser mais trabalhada.
\end{abstract}

Palavras-Chave: Ensino de Ciências - Oficinas de Ciências - Ecologia e Evolução.

\begin{abstract}
Teaching science means to privilege learning situations which enable the student to form their cognitive baggage. Science workshops can be used as didactic strategies, since they constitute an important mechanism to the construction of knowledge. The main objective of this study was to promote comprehension of concepts in Ecology and Evolution among students from Elementary and Secondary school through the development of workshops. During the activities, the majority of students participated and became interested. However, some points raised proved to be unknown, especially for Secondary Education students, what confirms how the teaching of Evolution still needs to receive more attention at schools, as well as Ecology must be better worked.
\end{abstract}

KeYwORDS: Science Education - Science Workshops - Ecology and Evolution.

\footnotetext{
${ }^{1}$ Mestranda do Programa de Pós-Graduação em Ecologia e Evolução da Universidade do Estado do Rio de Janeiro (UERJ). E-mail: larissamarques@ymail.com

${ }^{2}$ Pós-doutora em Neurociências - pelo Instituto de Ciências Biomédicas da Universidade Federal do Rio de Janeiro (2011). Professora de Ciências na Secretaria Municipal de Educação (SME) da Cidade do Rio de Janeiro e coordenadora da área de Ciências na plataforma de aulas digitais da SME - Educopédia. E-mail: lucineia@histo.ufrj.br
} 


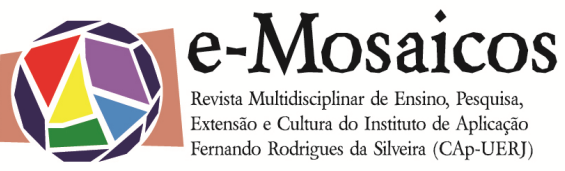

\section{INTRODUÇÃO}

A Ciência não consiste em um conjunto de resultados listados, assimilados através de uma mera escuta passiva, mas sim em uma atividade viva, engajada e sempre renovada (BAZIN, 1998, p. 27-38). Deste modo, ensinar ciências é privilegiar situações de aprendizagem que possibilitem ao aluno a formação de sua bagagem cognitiva. De acordo com a análise realizada por Vieira et al. (2005, p. 21-23), as aulas nãoformais atendem muito bem as expectativas do professor e, consequentemente, do aluno quando bem direcionadas e aproveitadas da forma como foi esperada por quem as planejou.

Segundo os Parâmetros Curriculares Nacionais - PNC (BRASIL, 1998, p. 1-139), a disciplina de Ciências deveria servir para uma reflexão e posterior investigação do meio que nos cerca, onde o aluno é o agente principal dessa ação. Portanto, a questão metodológica, a abordagem dos temas e conteúdos científicos apresentados por meio de diferentes recursos, e as estratégias e dinâmicas, são fatores que podem contribuir para o aprendizado em Ciências.

Os conceitos da biologia são fundamentais para que a humanidade saiba utilizar os recursos naturais de forma correta, promovendo a sua conservação. Tais conceitos nos ajudam a entender porque não devemos poluir os rios, contaminar o solo e o ar e a compreender que preservando os recursos naturais, estamos preservando nossa própria vida e a de todos os seres vivos.

As oficinas de Ciências podem ser utilizadas como estratégias didáticas que incentivam o aluno através da teoria e prática. A metodologia adotada em oficinas difere do foco tradicional de aprendizagem através da cognição ao incorporar a ação e a reflexão, dando oportunidade do aluno vivenciar ações concretas e significativas (PAVIANI \& FONTANA, 2009, p. 77-88). A proposta de uma oficina realizada com seriedade deve privilegiar além do espaço para que se aprenda fazendo, o pensar, o sentir, o intercâmbio de ideias, a problematização, o jogo, a investigação, a descoberta e a cooperação (VIEIRA \& VOLQUIND, 2002, p. 1-57). Atividades que adotam as oficinas pedagógicas como metodologia tornam mais eficiente a aprendizagem, pois estimulam a participação e o espírito de colaboração dos envolvidos, de maneira natural e espontânea, resultando numa melhor compreensão das questões abordadas. Os participantes das oficinas estimulam o espírito de colaboração, de parceria e organização das tarefas, contribuindo também para um crescimento social dos indivíduos. A criatividade também é estimulada, assim como a percepção e o desenvolvimento de habilidades para a elaboração de artefatos científicos e tecnológicos relacionados às Ciências e suas tecnologias (PEZENTE et al., 2012, p. 1).

Os conteúdos de Ecologia e Evolução ocupam posição central no conhecimento biológico, e são elementos importantes que devem ser enfatizados no ensino de Ciências. Os temas "origem e evolução da vida" bem como "o meio ambiente" devem ser abordados de forma frequente não só como conteúdo das aulas de Ciências, mas também por outras disciplinas.

A Ecologia pode ser compreendida como o estudo das interações dos organismos uns com os outros e com seus ambientes (RICKLEFS, 2010, p. 1-546). Ela é uma ciência que abraça elementos básicos para a compreensão das relações da espécie humana com seu entorno, e o seu ensino tem um sentido mais amplo quando a humanidade compreende a sua relação com a biosfera e começa a questionar-se quanto ao 
seu papel na conservação e degradação do ambiente em que vive (MANANZAL \& JIMÉNEZ, 1995, p. 2). Deste modo, desenvolver a consciência ecológica é um mecanismo fundamental para a compreensão de que os seres humanos habitam com todos os outros seres vivos um lar em comum, e que os atos praticados pelo homem comprometem direta ou indiretamente o equilíbrio do planeta.

A compreensão dos princípios da Ecologia e do Meio Ambiente e suas aplicações envolve o aluno em situações reais, o que contribui para a compreensão das múltiplas formas de interação dos organismos entre si e com o meio, das transformações que os organismos e o meio ambiente sofrem ao longo do tempo e no papel dos seres vivos e do homem nesses processos de alteração.

O ensino de Evolução é fundamental para a compreensão e entendimento das diferentes áreas da ciência, e, em grande parte das escolas, é considerado um tema polêmico, essencialmente por ser base para a explicação de fenômenos da vida. Por outro lado, este tema é um componente importante dos currículos de Biologia e Ciências, considerado um eixo integrador de conteúdos da área biológica (OLEQUES et al., 2011, p. 1-12).

A necessidade de diversificação das estratégias de ensino pode ser considerada um dos problemas relacionados ao ensino de evolução, visto que o uso de diferentes estratégias é um importante caminho para reduzir as dificuldades de compreensão do tema e aumentar a percepção sobre a importância para a biologia e seu ensino (OLIVEIRA \& GASTAL, 2013, p. 2574-2578). Segundo Corrêa et al. (2010, p. 217-237), as dificuldades de compreensão do conceito de evolução biológica demonstradas pelos alunos são consequência, entre outras cau- sas, dos equívocos conceituais e históricos presentes nos livros didáticos. Muitas vezes, tal recurso pedagógico aborda os aspectos evolutivos que deveriam ser uma das diretrizes para a construção do conhecimento biológico, como temáticas isoladas, presentes apenas nos últimos capítulos dos livros didáticos. Neste ponto, o emprego de oficinas como metodologia, tanto para o ensino de Ecologia quanto para Evolução, constitui um mecanismo importante na construção de conhecimento relacionado a esses temas, pois utilizam material didático diversificado que dinamiza as aulas, motivando os alunos a participarem ativamente na construção do próprio conhecimento.

O principal objetivo do presente trabalho foi levar os alunos da Educação Infantil e do Ensino Fundamental a compreender conceitos de Ecologia e Evolução, através do desenvolvimento de atividades práticas para que lhes seja despertado o interesse por questões relacionadas a estes dois conteúdos do Ensino de Ciências.

\section{Metodologia}

As oficinas de Ecologia e Evolução foram oferecidas aos alunos da Educação Infantil de duas escolas particulares, aos alunos do Ensino Fundamental regular de três escolas particulares e uma escola pública municipal e aos alunos da Educação de Jovens e Adultos de uma escola pública municipal, ambas no município do Rio de Janeiro, durante os anos letivos de 2011 e 2012.

As oficinas foram ministradas para grupos de no máximo 15 alunos, com duração de aproximadamente 30 minutos. A forma como os conteúdos das oficinas foram expostos foi adaptada de acordo com a faixa etária dos alunos. Para alunos com idade entre 4 e 5 anos em turmas de Educação Infantil, a abordagem foi realizada de 
forma mais prática e na parte teórica os temas relacionados ao cotidiano foram priorizados. Para os alunos de 6 a 15 anos nas turmas de Ensino Fundamental regular, tanto a parte teórica quanto a prática foram realizadas igualmente, sendo tanto a teoria quanto os assuntos do cotidiano tratados com a mesma ênfase. O mesmo foi realizado nas turmas de Educação de Jovens e Adultos, com idade entre 16 e 55 anos. Em ambas as oficinas, além da fundamentação teórica, foram realizadas também atividades práticas.

A oficina de Ecologia consistiu, em um primeiro momento, de uma apresentação teórica para os alunos se familiarizarem com os principais conceitos da Ecologia e Meio Ambiente. Esse momento era aberto para os mesmos relatarem experiências relacionadas com o tema vivenciadas no cotidiano, onde após responderem perguntas sobre preservação ambiental, os alunos expunham suas opiniões e dúvidas referentes ao assunto. No segundo momento, eram realizadas atividades práticas: o reaproveitamento de material descartado no lixo, que consistia na criação de objetos como portalápis, pulseiras e bolsas a partir de garrafas pet; a reciclagem de papel, em que folhas de papel usadas eram recicladas de modo a se tornarem úteis novamente; e separação de materiais que são passíveis de serem reciclados e reaproveitados, antes de serem descartados no lixo, em que os alunos separavam os materiais em papel, plástico, metal, vidro e orgânico. As atividades práticas foram elaboradas de forma a se assemelhar com futuras situações em que os mesmos poderão aplicar seus conhecimentos, focando em temas como reaproveitamento e reciclagem de materiais e coleta seletiva.

A oficina sobre conceitos de Evolução consistia, no primeiro momento, em uma abordagem teórica sobre as principais teorias da evolução, seleção natural, e a importância das descobertas fósseis, onde os alunos relatavam experiências anteriores relacionadas com os temas, como idas a museus, filmes, desenhos e documentários.

Os alunos observavam e manuseavam réplicas de fósseis, e, usando ferramentas paleontológicas, eles encontravam as réplicas em uma caixa representando um sítio arqueológico. As réplicas foram confeccionadas pelo Instituto de Geociências da Universidade de São Paulo (USP), e consistem em exemplares idênticos aos fósseis originais de Urogonphus giganteus do Jurássico, com procedência do Sul da Alemanha, dente do Tyrannosaurus rex do Cretáceo, com procedência da América do Norte, Elrathia kingii do Cambriano, com procedência dos Estados Unidos, Pecopteris do Carbonífero, com procedência de florestas tropicais e Archaeopteryx lithographica do Jurássico, com procedência da Alemanha.

Outra forma de abordagem era discutir curiosidades sobre a biologia e o comportamento dos dinossauros, mostrando modelos dos dinossauros conhecidos popularmente, adquiridos comercialmente, entre eles o Tyrannosaurus rex, dinossauro bípede, considerado um dos maiores predadores que já existiu; o Brachiosaurus sp., dinossauro quadrúpede, com pescoço muito longo e com patas dianteiras maiores que as traseiras; Stegosaurus armatus, dinossauro quadrúpede, com espigões ósseos na região dorsal utilizado para defesa e na termorregulação corporal; Triceratops horridus, dinossauro quadrúpede, com 3 chifres na cabeça de $2 \mathrm{~m}$ cada, utilizado para defesa e exibição sexual, e com bico para rasgar os vegetais de que se alimentava; Spinosaurus aegyptiacus, dinossauro bípede, com prolongações espinhais no dorso com diversas funções tais como: exibição sexual e intimidação de rivais; Pteranodon longiceps, di- 
nossauro voador, com asas de pele elástica, com ossos finos e ocos que os deixavam mais leves para voar, sendo pouco ágeis em terra firme.Os alunos da Educação de Jovens e Adultos assistiram também a um documentário, de aproximadamente 5 minutos, mostrando as condições da Terra no período Jurássico e, após a exibição deste, eram discutidas as causas da extinção dos dinossauros.

\section{RESULTADOS}

\section{PeRCEPÇÃo dos alunos dURANTE e APós as OFICINAS}

Com a finalidade de verificar a potencialidade das oficinas como forma eficiente de aprendizagem, buscamos identificar, na forma com que os alunos participaram das mesmas, indicativos que mostrassem a efetividade das oficinas, justificando sua importância como metodologia a ser adotada. Os resultados a seguir foram separados em oficina de Ecologia e oficina de Evolução, analisando separadamente a Educação Infantil, o Ensino Fundamental, e a Educação de Jovens e Adultos.

\section{- Oficina de Ecologia}

Nas turmas de Educação Infantil, observou-se que a maioria dos alunos, em algum momento, já havia ouvido falar sobre reciclagem, ainda que nenhum aluno soubesse diferenciar a reciclagem, a reutilização e o reaproveitamento de materiais (Fig.1B). Foi observado que grande parte da turma se mostrou muito entusiasmada durante a oficina, e a todo o momento os alunos manifestavam interesse em participar, principalmente com relatos de experiências com o reaproveitamento de materiais.

Durante a atividade prática de coleta seletiva (Fig.1A), foi observado, também diretamente, que um número reduzido de alunos não sabia separar os materiais na hora descartá-los no lixo, a principal dificuldade encontrada por eles foi identificar os materiais orgânicos. A atividade prática que mais despertou o interesse dos alunos foi a reciclagem do papel, provavelmente devido às mudanças ocorridas durante o processo, em que o papel já utilizado se dissolve em um meio liquido, e ao secar adquire a forma de uma folha.
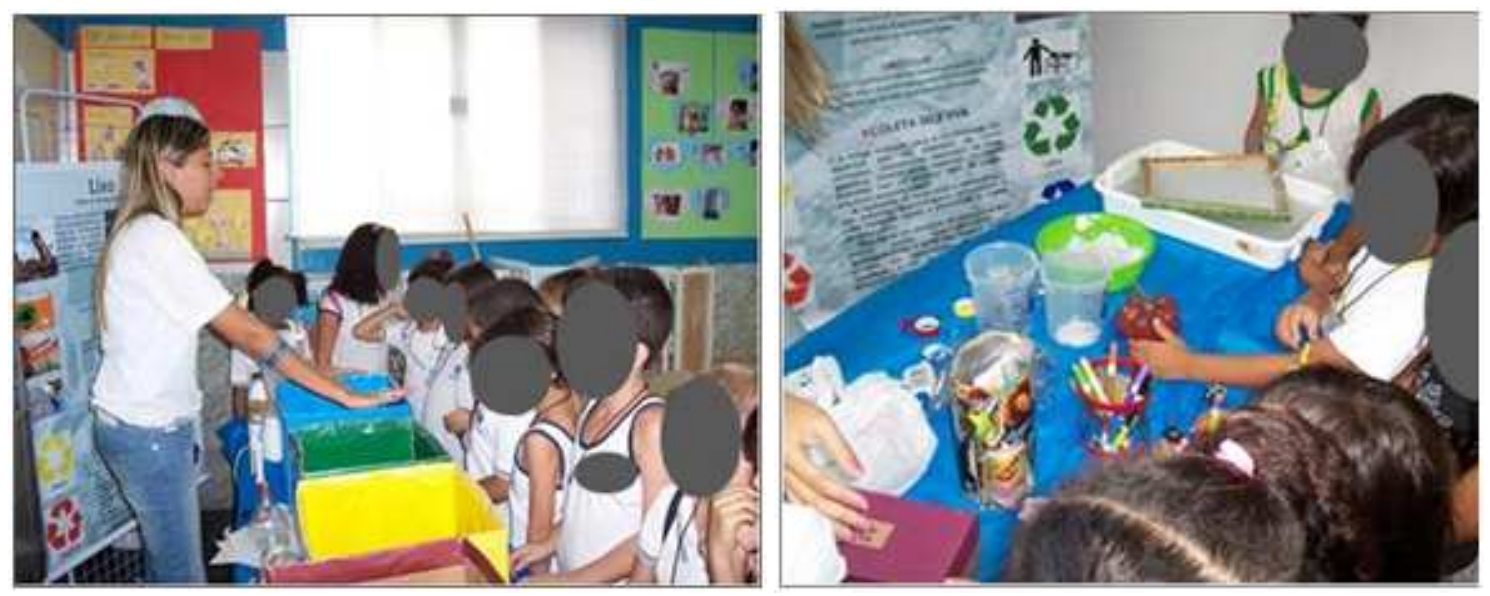

Figura 1. Realização de oficina de Ecologia na Educação Infantil. A: atividade prática sobre a coleta seletiva. B: atividade prática sobre a reutilização de materiais. 
No final da oficina, todos os alunos lembraram os conceitos abordados, e se mostraram dispostos a levar para o cotidiano, tanto dentro quanto fora da sala de aula, a coleta seletiva e a reciclagem e reaproveitamento de materiais.

Foi observado que nem todos os alunos do Ensino Fundamental conheciam os conceitos de Ecologia e meio ambiente, mas reconheciam a importância de preservar o meio ambiente. Também diretamente foi observado que a maioria da turma não sabia a diferença entre reciclar, reutilizar e reaproveitar, entretanto, grande parte dos alunos já tinha reaproveitado e reutilizado materiais, tanto na escola quanto no cotidiano. Tais experiências foram relatadas pelos mesmos, que contaram como e quais materiais haviam reaproveitado.
A atividade prática que mais despertou o interesse dos alunos foi a reutilização de garrafas pet para a produção de materiais úteis ao dia a dia (Fig.2A e 2B), como porta lápis, pulseiras e porta-moedas. A prática de reciclagem de papel era desconhecida da maioria dos alunos, e um grupo de alunos sugeriu ao resto da turma utilizar papel reciclado em trabalhos escolares. Observou-se que a maioria dos alunos sabia o que era coleta seletiva, mas não realizavam tal atividade nem na escola nem no dia a dia. No final da oficina, observou-se que grande parte da turma afirmou que vai levar os conceitos de Ecologia e meio ambiente e as práticas de reutilização de materiais, reciclagem de papel, e a coleta seletiva para o dia a dia e para a sala de aula.
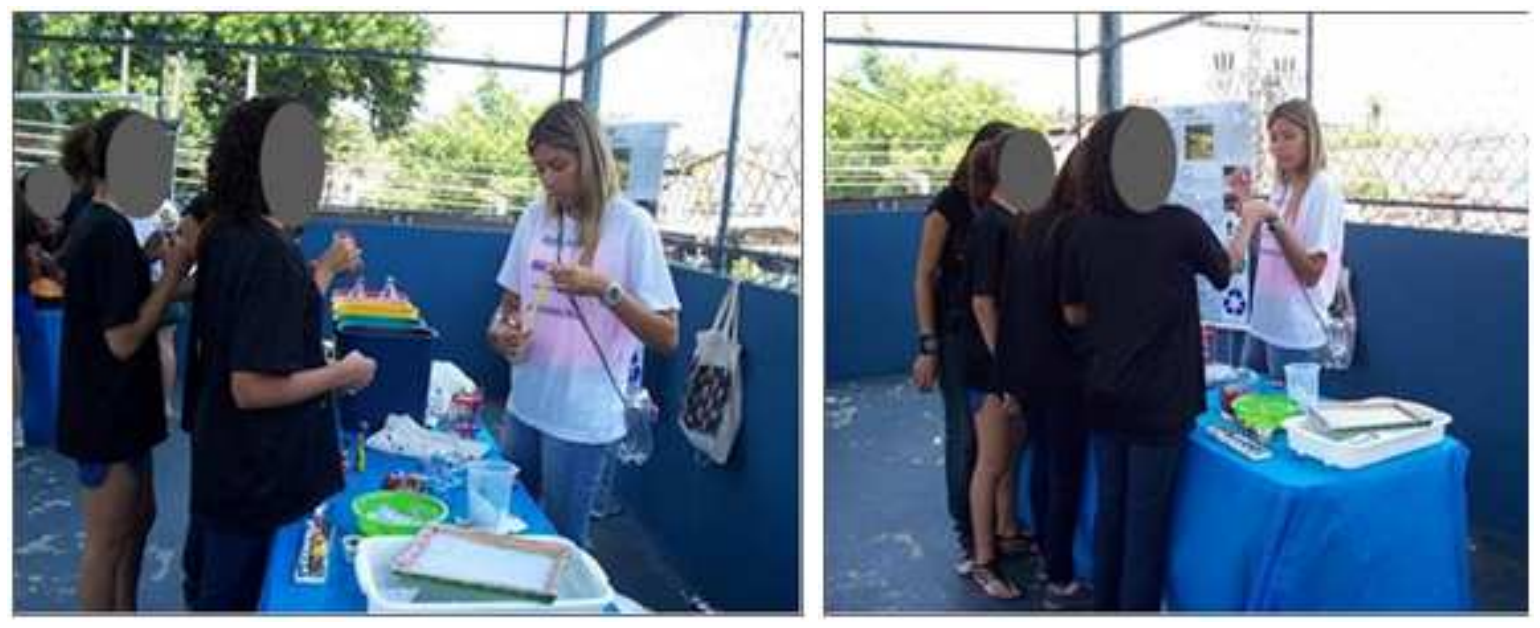

Figura 2. Realização de oficina de Ecologia no Ensino Fundamental. A e B: atividade prática sobre a reciclagem, reutilização e redução do lixo para alunos do $6^{\circ}$ Ano.

\section{- Oficina de Evolução}

Para os alunos de Educação Infantil, os principais conceitos abordados foram sobre a evolução dos seres vivos e o surgi- mento e extinção dos dinossauros. Observou-se que a maioria da turma participou ativamente na parte teórica e prática, principalmente nos temas que envolviam dinos- 
sauros (Fig.3). Observou-se também que uma parte dos alunos sabia o nome cientifico de alguns dos dinossauros, e também conheciam alguns de seus hábitos. A maior parte das perguntas também foi em relação aos dinossauros e seus hábitos. Grande parte dos alunos não sabia o que eram fósseis, e ficaram muito entusiasmados na prática de usar ferramentas paleontológicas para procurar fósseis no sítio arqueológico. Alguns alunos inclusive manifestaram interesse em participar mais de uma vez dessa prática. No final da oficina foi observado diretamente que a maioria lembrou os conceitos abordados, como o que são fósseis e qual a importância dessas descobertas para a ciência, assim como as possíveis causas da extinção dos dinossauros.

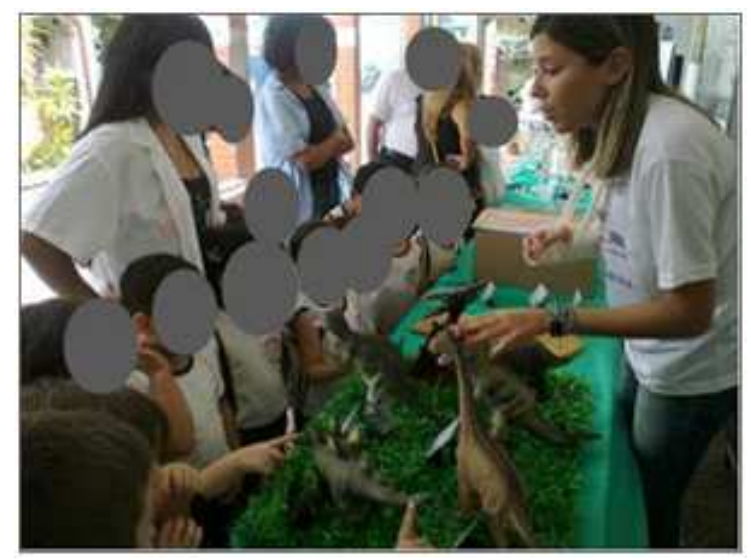

Figura 3. Realização da oficina sobre conceitos de evolução na Educação Infantil. Ensino sobre a evolução dos seres vivos, ressaltando a existência dos dinossauros e sua extinção.

Foi observado que nem todos os alunos do Ensino Fundamental souberam relatar como os seres vivos surgiram, e nem como evoluíram durante muitos bilhões de anos. Em relação aos naturalistas que propuseram as principais teorias a respeito da evolução dos seres vivos, foi observado que um número reduzido de alunos já tinha ouvido, em algum momento, a respeito de Darwin, mas foi observado que a maioria não sabia quais foram suas principais contribuições para a ciência. Também foi observado que nenhum aluno havia ouvido falar sobre Lamark, nem sobre sua teoria da evolução dos seres vivos. Foi observado que a turma, como um todo, realizou muitas perguntas sobre as teorias de evolução e sobre os naturalistas já citados.

Durante a prática para achar réplicas fósseis, usando ferramentas paleontológicas (Fig.4A), os alunos ficaram muito interessados, mesmo que alguns alunos tenham aprendido o que são fósseis naquele momento. Alguns alunos citaram documentários e filmes, relacionando tais fontes de informação com o conteúdo da Oficina, principalmente quando os assuntos relacionados aos dinossauros e às descobertas fósseis foram citados.

Foi observado que a maioria da turma sabia explicar as possíveis causas da extinção dos dinossauros, bem como nome e o comportamento de algumas espécies. No final da oficina, observou-se que grande parte dos alunos lembrou os conceitos abordados, inclusive conceitos antes desconhecidos por eles, como a teoria da evolução de Darwin e Lamark e a importância das descobertas fósseis. 

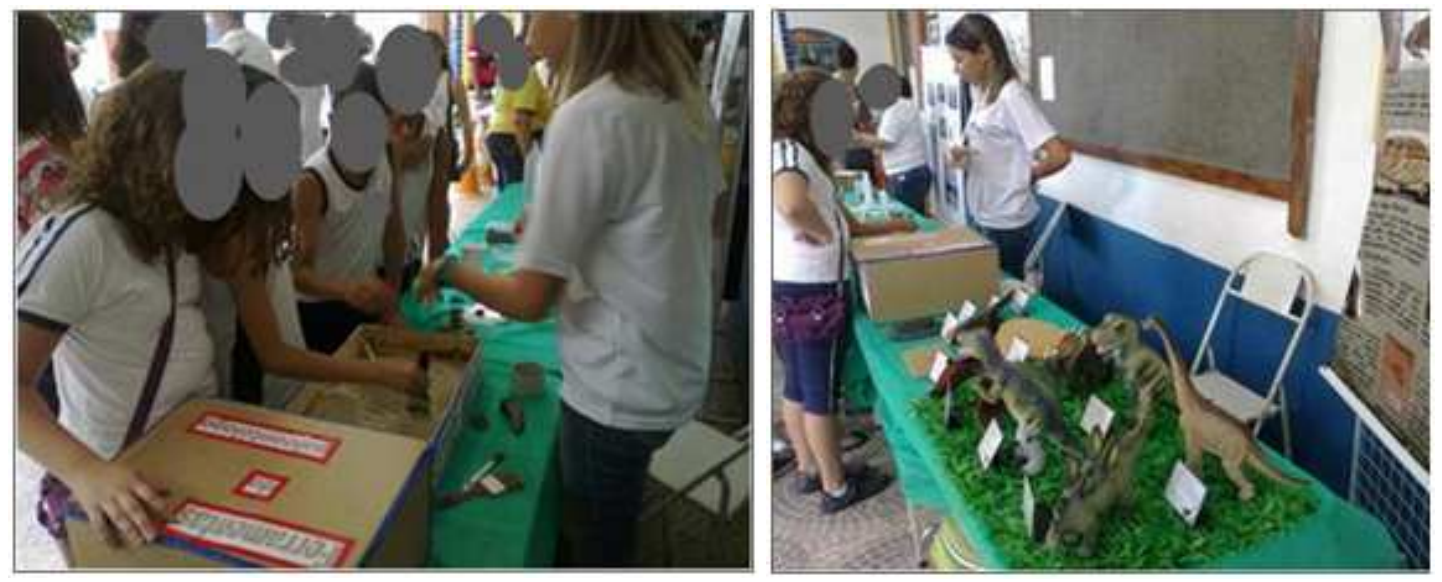

Figura 4. Realização da oficina sobre conceitos de evolução no Ensino Fundamental. A: atividade prática sobre os fósseis - evidências da evolução para alunos do $5^{\circ}$ Ano. B: ensino sobre a evolução dos seres vivos para alunos do $5^{\circ}$ Ano.

As turmas da Educação de Jovens e Adultos participaram ativamente, tanto na parte teórica, quanto na parte prática das oficinas (Fig.5B). Foi observado que a maioria dos alunos conhecia as teorias evolutivas, muitos sabiam quem era Darwin e como ele contribuiu para a ciência, mas nenhum aluno sabia quem era Lamark. Foi observado também que alguns alunos realizaram perguntas em relação às teorias evolutivas, e como tais teorias contribuíram para a ciência.

Observou-se que a grande parte da turma sabia o que era um fóssil e como as descobertas fósseis contribuem para a ciência. Entretanto, os alunos desconheciam que para ser caracterizado como fóssil, o achado deve pertencer a seres vivos que viveram há mais de 11.000 anos. Na prática de descoberta fóssil no sítio arqueológico, somente alguns alunos mostraram interesse em participar, e, ao acharem o fóssil, eles leram suas características para a outra parte da turma, e identificaram a que animais os fosseis pertenciam. Foi observado que, com exceção de poucos alunos, a maioria da turma sabia as adaptações dos dinossauros, o nome de algumas espécies e as possíveis causas da sua extinção.

Os alunos lembraram algumas informações aprendidas em sala de aula em relação às Eras Geológicas e as condições da Terra no Período Jurássico, e também narraram algumas curiosidades relacionadas com as adaptações de vida dos dinossauros, que eles aprenderam durante uma visita da turma a um museu, onde eles puderam, inclusive, visualizar o esqueleto de um dinossauro. Foi observado também que a maioria da turma se interessou em ver o documentário que mostra as condições da Terra no período Jurássico (Fig.5A).

No final da oficina, a turma relembrou os conceitos abordados durante a ofi- 
cina, os alunos também apontaram as diferenças entre as teorias de Darwin e Lamark,

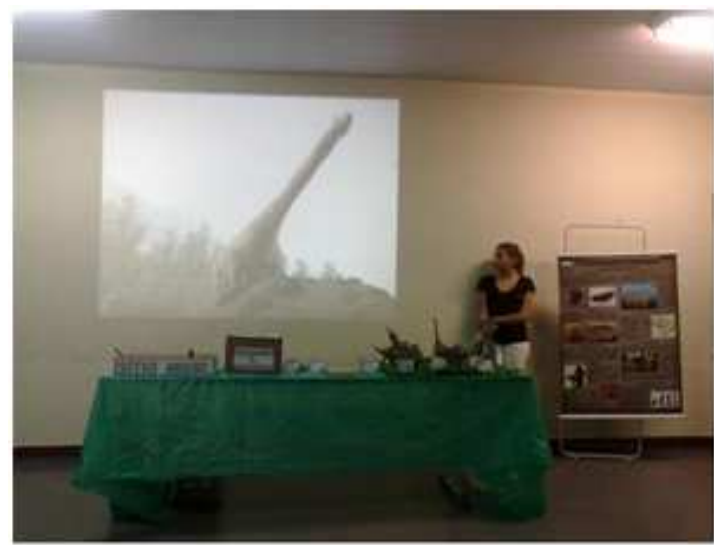

e fizeram alguns comentários finais sobre o que foi mostrado no documentário.

Figura 5. Realização da oficina sobre conceitos de evolução na Educação de Jovens e Adultos (EJA). A: documentário sobre os dinossauros. B: ensino sobre a evolução dos seres vivos.

\section{CONSIDERAÇÕES FINAIS}

A realização de atividades práticas no ensino de Ciências é de grande importância na aprendizagem de qualquer aluno do Ensino Fundamental, seja este criança, jovem ou adulto. Smith, 1975 apud Carvalho et al. (1998, p. 20-23) afirma que a importância do trabalho prático é inquestionável na Ciência e deveria ocupar lugar central no seu ensino. Abou-Saab \& Godoy (2009, p. 1-20) dizem que as atividades práticas experimentais são de extrema relevância para a aprendizagem dos conteúdos por parte dos educandos e Andrade \& Massabni (2011, p. 835-854) afirma que essas atividades contribuem para o interesse e a aprendizagem em Ciências.

Durante as atividades realizadas neste trabalho, a maioria dos alunos, tanto da Educação Infantil, quanto do Ensino Fundamental, incluindo a Educação de Jovens e Adultos, se mostraram participativos e interessados, principalmente durante as ativida-

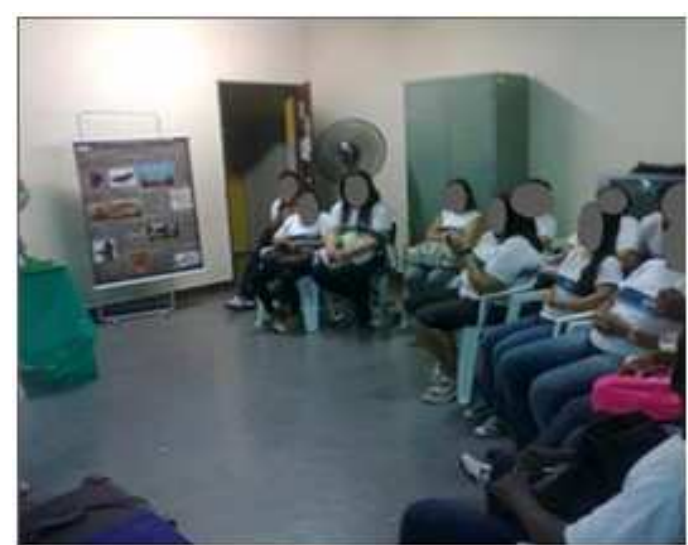

des práticas.

Foi observada uma predileção da maioria dos alunos pelo tema reciclagem e dinossauros nas oficinas de Ecologia e Evolução, respectivamente, que pode estar relacionada com a popularização de ambos os assuntos, que são mais amplamente discutidos na mídia e no cotidiano. Muitos alunos apresentaram questionamentos e relembraram conceitos abordados em sala de aula, bem como situações vivenciadas no dia a dia.

Segundo Ramos \& Sá (2013, p. 123140), o fato do mediador não ser o professor da turma influencia no nível de desenvoltura dos alunos, que podem se mostrar resistentes à participação. Este fato foi observado na turma da Educação de Jovens e Adultos no início da prática da Oficina de Evolução. Entretanto, a turma logo se mostrou participativa e ainda pudemos observar um grande interesse desta durante a exibi- 
ção do documentário, o que pode sugerir a exibição de filmes como uma ferramenta pedagógica bastante útil na aprendizagem dos alunos deste segmento. Assim como observado por Souza et al. (2012, p. 1-5), as práticas realizadas durante as oficinas, tornam a aula mais agradável e dinâmica, motivando os alunos a participarem ativamente da construção do próprio conhecimento. Tais participações foram observadas durante e após as oficinas, onde foi possível concluir que os alunos, além de se aprofundarem nos temas propostos, relembraram o que foi exposto durante as atividades.

Alguns pontos abordados, como as teorias evolutivas e a importâncias dos fósseis mostraram ser desconhecidos, principalmente para alunos do Ensino Fundamental, o que confirma o quanto o ensino da Evolução ainda precisa receber mais atenção nas escolas, assim como a Ecologia deve ser mais trabalhada, estimulando uma compreensão mais profunda da razão da preservação do meio ambiente e seu funcionamento.

A popularidade de Darwin entre os alunos pode estar relacionada com a contribuição do naturalista para o desenvolvimento da teoria da evolução e por estar entre os cientistas mais conhecidos do século XXI. Se comparados, Darwin e sua teoria têm muito mais destaque nas principais mídias, incluindo exposições e eventos culturais e científicos, enquanto que Lamark, mesmo tendo exercido papel fundamental na ciência evolutiva, é pouco lembrado em locais de ensino não formal, sendo mais citado dentro da sala de aula.

\section{REFERÊNCIAS BIBLIOGRÁFICAS:}

ABOU-SAAB, L. A. \& M. T. GODOY. Experimentação nas aulas de Biologia e a apropriação do saber. Ponta Grossa, p. 1
- 20, 2009. Disponível em: http://www. diaadiaeducacao.pr.gov.br/portals/pde/ arquivos/446-4.pdf?PHPSESSID $=20090507$ 08092673. Acesso em: 14 de abril de 2014. ANDRADE, M. L. F. \& V. G. MASSABNI. O desenvolvimento de atividades práticas na escola: um desafio para os professores de Ciências. Ciência \& Educação, Bauru, v. 17, n. 4, p. 835 - 854. 2011.

BAZIN, M. Ciência na nossa cultura? Uma práxis de educação em ciências e matemática: oficinas participativas. Educar em Revista, Curitiba, n.14, p. 27 - 38, 1998.

BRASIL. Secretaria de Educação Fundamental. Parâmetros Curriculares Nacionais: Ciências Naturais. Brasília: MEC/SEF, p. 1-139, 1998.

CARVALHO, A. M. P., A. I. VANNUCCHI, M. A. BARROS, M. E. R. GONÇALVES \&, R. C. REY. Ciências no Ensino Fundamental: O conhecimento físico. $1^{a}$. ed. Editora Scipione, São Paulo, p. 22-23, 1998.

CORRÊA, A. L. et al. História e Filosofia da Biologia como ferramenta no Ensino de Evolução na formação inicial de professores de Biologia. Revista Filosofia e História da Biologia, São Paulo, v. 5, n. 2, p. 217-237, 2010.

MANANZAL, R. F. \& JIMÉNEZ, M. C. La ensenãnza de La ecologia. Un objetivo de La educacion ambiental. Ensenãnza de lãs ciências, v. 13, n. 3, p. 259-311, 1995.

OLEQUES, L. C. et al. Evolução Biológica como Eixo Integrador no Ensino de Biologia: Concepções e Práticas de Professores do Ensino Médio. In: VIII ENCONTRO NACIONAL DE PESQUISA EM EDUCAÇÃO EM CIÊNCIAS, UNICAMP. Campinas, p. 1-12, 2011. Disponível em: 
<http://www.nutes.ufrj.br/abrapec/viiienpec /resumos/R1066-1.pdf> Acesso em: 04 nov. 2013.

OLIVEIRA, R. I. R.; GASTAL, M. L. A. Estudos do Meio em Trilhas Ecológicas para o Ensino de biologia Evolutiva. Universidade de Brasilia, IX Congresso Internacional sobre investigación em didáctica de las Ciencias. p. 2574-2578, 2013.

PAVIANI, N. M. S.; FONTANA, N. M. Oficinas Pedagógicas: relato de uma experiência. Revista Conjectura: filosofia e educação, Rio Grande do Sul, v.14, n.2, p.77-88, 2009.

PEZENTE, M. T. et al. O processo de ensinoaprendizagem através de oficinas pedagógicas. Revista Técnico Científica (IFSC), Santa Catarina, v.3, n. 1, p.1, 2012.

RAMOS, L. C.; SÁ, L. P. A alfabetização científica na Educação de Jovens e Adultos em atividades baseadas no programa "mão na massa". Revista Ensaio, Belo Horizonte, v. 15, n. 2, p. 123-140, 2013.

RICKLEFS, R. E. A economia da natureza. 6. ed. Rio de Janeiro: Guanabara Koogan, 2010, p. 1-546.

SOUSA, E. M.; SILVA, F. O.; SILVA, T. R. S.; SILVA, P. H. G. A Importância das Atividades Lúdicas: uma proposta para o ensino de Ciências. In: VII Congresso Norte Nordeste de Pesquisa e Inovação. Tocantins, p. 1-5, 2012. Disponível em: <http://propi.ifto.edu.br/ocs/index.php/con nepi/vii/paper/viewFile/3948/2742>. Acesso em: 29 nov. 2013.

VIEIRA, E.; VOLQUIND, L. Oficinas de ensino: $O$ quê? Por quê? Como? 4. ed. Porto Alegre: Edipucrs, p. 1-57, 2002.

VIEIRA, V.; BIANCONI, M. L.; DIAS, M. Es- paços não-formais de ensino e o currículo de ciências. Ciência e Cultura, São Paulo, v. 57, n. 4, p. 21-23, 2005. Disponível em <http://cienciaecultura.bvs.br>. Acesso em: 30 out. 2013. 